\title{
Allometric Laws and Prediction in Estuarine and Coastal Ecology
}

\author{
Lora A. Harris ${ }^{1 *}$, Carlos M. Duarte ${ }^{2}$, and Scott W. Nixon ${ }^{1}$ \\ ${ }^{1}$ Graduate School of Oceanography, University of Rhode Island, Narragansett, Rhode Island 02882 \\ ${ }^{2}$ Grup d'Oceanografia Interdisciplinar, IMEDEA (CSIC-UIB) Institut Mediterrani d'Estudis Avançat, \\ C/Miquel Marqués 21, 07190 Esporles, Illes Balears, Spain
}

\begin{abstract}
A theoretical and quantitative framework of first principles would benefit estuarine and coastal ecologists in search of predictions to enhance our understanding and management of marine resources. The Metabolic Theory of Ecology describes a possible unifying theory for ecology, including mechanistically derived equations that predict scaling exponents observed in empirical, allometric relationships from individuals to ecosystems. The controversy surrounding this theory should stimulate our exploration of its potential use in the coastal realm, where questions specific to an applied science may suggest new refinements and derivations, contributing to the overall progress of ecology.
\end{abstract}

\section{Introduction}

The interaction between nature and society is more direct and stronger in estuaries and coastal systems than elsewhere in the marine environment. This has led to urgent calls from coastal managers and policy makers for the scientific community to seek increased predictive capacity to deal with issues such as climate change, nutrient enrichment, species introductions, and overharvesting. Often these calls find us unresponsive or less than helpful. The reason for this may be, as Peters (1991) pointed out, that ecologists are often overwhelmed by the complexity of the systems they study, which often inhibits the development of quantitative hypotheses and predictive theories. The proliferation of untestable qualitative theories in our scientific literature does not provide the firm ground from which we might advise the managers or advance our science. We need to find a better balance between understanding of the detail and prediction of higherlevel behavior of ecosystems in an effort to move towards a set of ecological first principles (Harte 2002).

The goals of prediction and understanding were considered not long ago to be end members of a trade-off difficult to reconcile in ecology (Lehman 1986; Peters 1986). The ensuing debate in limnology showed similarities to an earlier argument made by Levins (1966) that trade-offs in population models between achieving generality, precision, and realism were inevitable. These perceived roadblocks have led to a widespread pessimism in the capacity to generate predictions in ecology. The emphasis for ecological models has shifted from

\footnotetext{
* Corresponding author; current address: Ecosystems Center, Marine Biological Laboratory, 7 M B L Street, Woods Hole, Massachusetts 02543; tele: 508/289-7716; fax: 508/457-1548; e-mail: lharris@mbl.edu
}

prediction, considered an unattainable goal, to forecasting (see Clark et al. 2001), which reflects an uncommitted expectation that stresses various estimates of associated uncertainty rather than a falsifiable prediction. New developments that seek prediction from a solid basis of understanding provide new hope. One approach, described here, is the recently proposed metabolic theory of ecology (MTE, Brown et al. 2004), which aims at providing predictions of functional processes and responses of communities and ecosystems from thoroughly understood physiological principles governing the allometric scaling of organismal metabolism. Our purpose here is to raise awareness in the estuarine and coastal research community of this exciting development and the opportunities it may offer to support much needed predictive capacity with a solid underpinning of understanding. We do so by providing examples of its application that might stimulate further explorations.

Prediction is not an unattainable goal in ecology, as demonstrated by the successful use of allometric power laws to predict functions and traits of both plants (Niklas 1994) and animals (Peters 1983). It is not surprising that allometric laws are being revisited as the basis to predict not only individual organism properties (Eqs. 1-5 in Table 1), but energy and material flows in whole ecosystems (Eqs. 6-10 in Table 1). The MTE shows promise as a quantitative starting point for ecologists (Brown et al. 2004), while also provoking much discussion and debate, largely in terrestrial ecology (Agrawal 2004). The MTE builds on long recognized allometric relationships between body size and metabolism now evident across 27 orders of magnitude in body mass for both plants and animals in aquatic and terrestrial ecosystems (West et al. 1997; Savage et al. 2004). According to these scaling laws, individual primary production, standing stock biomass, and 
TABLE 1. Allometric equations. Specific derivations are referenced and most are described with greater detail in Brown et al. (2004).

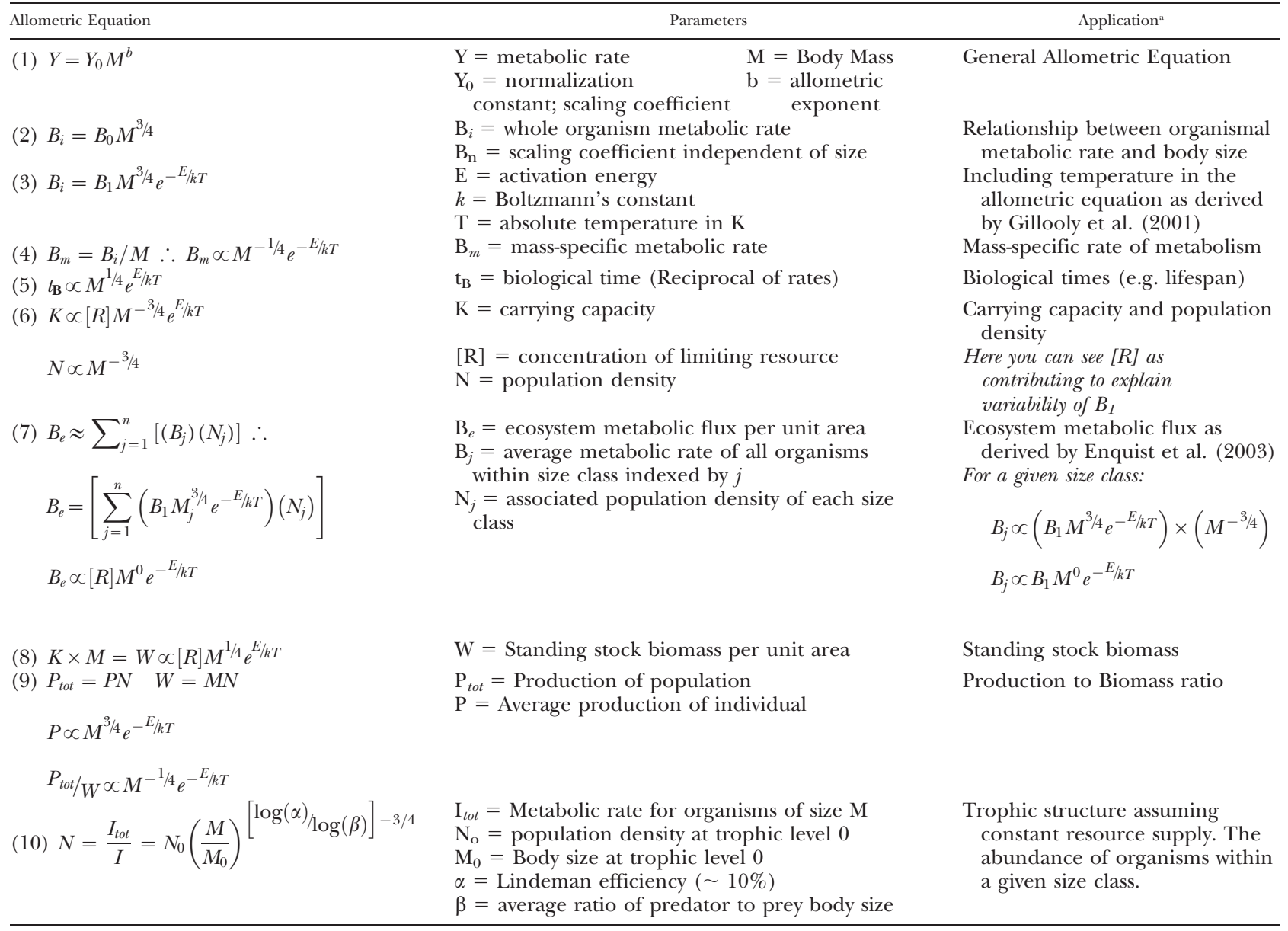

respiration scale by roughly the $3 / 4$ power of organismal size (cf., Peters 1983; Niklas 1994). While the MTE is based in the rich intellectual history of animal metabolism (Kleiber 1932; Brody 1945), it derives its scaling laws from first principles outlined by West et al. (1997, 1999a,b), extended to include the effects of temperature by Gillooly et al. (2001). Its mechanistic predictive power arises from the constraints imposed on branched energy delivery systems (e.g., circulatory systems) present in all forms of life that maximize capacity and efficiency through fractal geometry (West et al. 1999a). These systems have converged under evolutionary pressures to optimize energy flow, as functions of body size and temperature. It is this mechanistic understanding of metabolism, phrased as the quantitative model of West et al. (1997, 1999a,b), that allows allometric statistical regressions between life history and functional characteristics to be expanded to an entire suite of predictive equations that are connected with one another by the assumptions of the MTE. This is a fundamental shift in how allometric predictive equations are derived. All of the equations in Table 1 can be derived from one another without the benefit of data sets; the scaling exponents predicted from theory may then be submitted to an empirical test for validation. These equations offer a formidable toolbox for the coastal ecologist to deliver predictive capacity with the potential for new derivations and equations that may be tailored to questions specific to our field.

Whereas individual organisms were the focus of allometric scaling laws in the past, the key to the power of the MTE approach lies in extending these laws from individual organisms to entire communities and ecosystems. This extension provides a link between traditionally isolated research programs, namely individual-based models and ecosystem models that encompass many components of food webs. In doing so, predictions become available at the more relevant scale of the ecosystem, while 
including the robustness of the physical and physiological underpinnings of how these laws operate at the individual level. The resulting ecological patterns are partially explained by the performance of the individuals within an ecosystem and their combined metabolic rates (Enquist et al. 2003). These predictions can be potentially extended to the coastal environment, because the distribution of animal and plant sizes in aquatic ecosystems follows quasi-universal patterns expected from energetic considerations (e.g., Eq. 10 in Table 1). The size spectra describing these patterns in marine systems have revealed roughly equivalent biomass in logarithmic size classes (Kerr and Dickie 2001), which can be described using a Pareto distribution as detailed in Vidondo et al. (1997). Indeed, an entire session of the 2005 American Society of Limnology and Oceanography international meeting was devoted to investigating the size structure of plankton communities (American Society of Limnology and Oceanography unpublished data).

The solid conceptual link provided by these new uses of allometric scaling has illuminated other commonly observed patterns, including declining abundance with increasing trophic level (e.g., Brown and Gillooly 2003), the thinning law in vascular plants (Enquist et al. 1998), and the scaling of growth to average plant size (Nielsen et al. 1996). Although these developments are not specific to the coastal realm, we believe that they offer promising avenues to address bottlenecks in our capacity to predict relevant properties of coastal ecosystems. In particular, estuarine modelers are challenged with the difficulty of linking models of ecosystem dynamics at the microbial level, which are often driven by biogeochemical constraints, with fisheries models often dependent on organismal demography. Although an ecosystem approach to fisheries has long been advocated (e.g., Laevastu and Larkins 1981), the specific paths enabling such an approach remain obscure or have been limited to predatorprey interactions (Latour et al. 2003). This may be ripe for change with applications of the emerging MTE models. Trophically-explicit MTE models have been applied to estimate fish abundance in the North Sea in the absence of fishing pressures (Jennings and Blanchard 2004) and to estimate the size structure of benthic infaunal communities (Dinmore and Jennings 2004). MTE models also allow for explicit consideration of food web structure, improving predictions of energy flow at the ecosystem level (Table 1) and providing an alternative validation technique for existing fisheries ecosystem approaches (i.e., Ecopath with Ecosim, Pauly et al. 2000).
Because the constraints to metabolism are universal across organisms, the formulation of models that rest upon such rules helps address metabolic processes at both the individual and the ecosystem level in a concerted manner. MTE models may provide additional insight into the regulation of ecosystem metabolism, which is currently addressed following a black box approach, and help to resolve current controversies regarding respiration and oceanic carbon cycling (del Giorgio and Duarte 2002). Global warming is expected to raise air temperatures by about $3-4^{\circ} \mathrm{C}$ this century (IPCC 2001), with less certain projections of increased sea surface temperatures between $1-3^{\circ} \mathrm{C}$ (Pittock 1999; Scavia et al. 2002) likely to be higher in coastal areas. Because the MTE models explicitly consider the role of temperature in regulating ecosystem metabolism (Table 1), these models offer a convenient avenue to predict the expected response of energy flow in coastal food webs to global warming. Because the activation energies for autotrophs are half that of heterotrophs, examination of Eq. 7 (Table 1) reveals that for every degree increase in temperature we can expect heterotrophic respiration to increase at twice the rate of net primary production rates leading to a potential decrease in heterotroph biomass. Hypothetically, a four degree increase in the summer water temperatures of a northeastern Atlantic estuary will result in a $20 \%$ increase in net primary production and a $43 \%$ increase in heterotrophic metabolism, resulting in a $16 \%$ decrease of the $P: R$ ratios and an increasing likelihood of system heterotrophy.

The lively debate surrounding the MTE has challenged its participants in a thorough conceptual, empirical, and mathematical test that has engaged the broader ecological and biological communities. Its critics have offered disagreement over the numerical value of scaling exponents (Dodds 2001), concern over the uncertainty of the predictions, which may be masked by the multilogarithmic representation of the scaling relationships (Tilman et al. 2004), and an argument for phenomenological versus mechanistic conceptual roots (Cyr and Walker 2004). We believe that much of this disagreement stems from questions regarding how residual unexplained variability resulting from application of the MTE model can be addressed. At the very least, the large proportion of variability present in an estuarine system that can be explained by body size, temperature, and trophic level may allow us to isolate components of the residual variability explained by other factors. An analysis of MTE residuals versus resource availability may help address resource constraints on ecosystem functioning once the role of temperature, body size, and trophic level have been accounted for as has 
been demonstrated in the case of phytoplankton (Finkel et al. 2004).

The potential to transfer insights gained from use of the MTE for applied problems will continue to require interpretation for policy makers and managers along with basic scientific education and training focused on ecological models and their use, as has been advocated for all modeling endeavors (Canham et al. 2003). Use of the MTE in applied problems has already been documented for fisheries (Dinmore and Jennings 2004; Jennings and Blanchard 2004) in an effort to gauge the relative impact of bottom-up effects versus overfishing on fish abundance. The MTE is particularly suitable for questions involving resource use, energy, and temperature as demonstrated in a recent example by Vasseur and McCann (2005) who incorporated the Boltzmann factor into a model of consumer-resource dynamics. We foresee the development of new applications and improved MTE models as a promising avenue to link organismalbased models with ecosystem-based processes, undoing a Gordian knot of ecology to extend existing predictive capacity at the organismal level to the behavior of coastal and estuarine systems.

\section{ACKNOWLEDGMENTS}

Two anonymous reviewers provided constructive comments that greatly improved the manuscript. L. Harris was partly funded by the Cove Point Foundation and benefited from a travel grant to attend the 2004 Gordon Research Conference on the Metabolic Basis of Ecology, funded by the National Science Foundation. This material is based upon work by L. Harris supported by the National Science Foundation under Grant No. DEB 0213767 and OCE 9726921. This research is a contribution to the MarBEF Network of Excellence, funded by the European Union.

\section{Literature Cited}

Agrawal, A. A. 2004. Special Features Editor at Estuaries for the Forum on the Metabolic Theory of Ecology. Ecology 85:17711821.

BRODY, S. 1945. Bioenergetics and Growth, with special reference to the efficiency complex in domestic animals. Reinhold, New York.

Brown, J. H. AND J. F. GiLlooly. 2003. Ecological food webs: Highquality data facilitate theoretical unification. Proceedings of the National Academy of Sciences (USA) 100:1467-1468.

Brown, J. H., J. F. Gillooly, A. P. Allen, V. M. Savage, And G. B. WEST. 2004. Toward a metabolic theory of ecology. Ecology 85: 1771-1789.

Canham, C. D., J. J. Cole, and W. K. Lauenroth (eds.). 2003, Models in Ecosystem Science. Princeton University Press, Princeton, New Jersey.

Clark, J. S., S. R. Carpenter, M. Barber, S. Collins, A. Dobson, J. A. Foley, D. M. Lodge, M. Pascual, R. Pielke, JR., W. Pizer, C. Pringle, W. V. Reid, K. A. Rose, O. Sala, W. H. Schlesinger, D. H. Wall, and D. Wear. 2001. Ecological forecasts: An emerging imperative. Science 293:658-660.

Cyr, H. and S. C. Walker. 2004. An illusion of mechanistic understanding. Ecology 85:1802-1804.
Del Giorgio, P. A. And C. M. Duarte. 2002. Respiration in the open ocean. Nature 420:379-384.

Dinmore, T. A. AND S. JenNings. 2004. Predicting abundance-body mass relationships in benthic infaunal communities. Marine Ecology Progress Series 276:289-292.

Dodds, P. S., D. H. Rothman, and J. S. Weitz. 2001. Reexamination of the ' $3 / 4$ law' of metabolism. Journal of Theoretical Biology 209:9-27.

EnQuist, B. J., J. H. Brown, ANd G. B. West. 1998. Allometric scaling of plant energetics and population density. Nature 395: 163-165.

Enquist, B. J., E. P. Economo, T. E. Huxman, A. P. Allen, D. D. IGNACE, AND J. F. GILlooly. 2003. Scaling metabolism from organisms to ecosystems. Nature 423:639-642.

Finkel, Z. V., A. J. Irwin, AND W. Schofield. 2004. Resource limitation alters the $3 / 4$ size scaling of metabolic rates in phytoplankton. Marine Ecology Progress Series 273:269-279.

Gillooly, J. F., J. H. Brown, G. B. West, V. M. Savage, and E. L. CHARNov. 2001. Effects of size and temperature on metabolic rate. Science 293:2248-2251.

HARTE, J. 2002. Toward a synthesis of the Newtonian and Darwinian world views. Physics Today 55:29-35.

Intergovernmental Panel on Climate Change (IPCC). 2001. Climate change 2001: A summary report. IPCC, Wembley, U.K.

Jennings, S. AND J. L. Blanchard. 2004. Fish abundance with no fishing: Predictions based on macroecological theory. Journal of Animal Ecology 73:632-642.

KerR, S. R. AND L. M. Dickie. 2001. The Biomass Spectrum. Columbia University Press, New York.

KLEIBER, M. 1932. Body size and metabolism. Hilgardia 6:315-353.

Laevastu, T. and H. A. LaRkins. 1981. Marine Fisheries Ecosystem: Its Quantitative Evaluation and Management. Fishing News Books Ltd, Norwich, U.K.

Latour, R. J., M. J. Brush, and C. F. Bonzek. 2003. Toward ecosystem-based fisheries management: Strategies for multispecies modeling and associated data requirements. Fisheries 28:1022.

Lehman, J. T. 1986. The goal of understanding in limnology. Limnology and Oceanography 31:1160-1166.

LEVINS, R. 1966. The strategy of model building in population biology. American Scientist 54:423-431.

Nielsen, S. L., S. Enríguez, C. M. Duarte, and K. SAnd-Jensen. 1996. Scaling of maximum growth rates across photosynthetic organisms. Functional Ecology 10:167-175.

NikLAS, K. J. 1994. Plant Allometry: The Scaling of Form and Process. University of Chicago Press, Chicago, Illinois.

Pauly, D., V. Christensen, and C. Walters. 2000. Ecopath, Ecosim, and Ecospace as tools for evaluating ecosystem impact of fisheries. ICES Journal of Marine Science 57:697-706.

Peters, R. H. 1983. The Ecological Implications of Body Size. Cambridge University Press, Cambridge, U.K.

PETERS, R. H. 1986. The role of prediction in limnology. Limnology and Oceanography 31:1143-1159.

Peters, R. H. 1991. A Critique For Ecology. Cambridge University Press, New York.

Piтtock, A. B. 1999. Coral reefs and environmental change: Adaptation to what? American Zoologist 39:10-29.

Savage, V. M., J. F. Gillooly, W. H. Woodruff, G. B. West, A. P. Allen, B. J. Enguist, and J. H. Brown. 2004. The predominance of quarter-power scaling in biology. Functional Ecology 18:257-282.

Scavia, D., J. C. Field, D. F. Boesch, R. W. Buddemeier, V. Burkett, D. R. Cayan, M. Fogarty, M. A. Harwell, R. W. Howarth, C. Mason, D. J. Reed, T. C. Royer, A. H. Sallenger, AND J. G. TITUS. 2002. Climate change impacts on U.S. coastal and marine ecosystems. Estuaries 25:149-164.

Tilman, D., J. Hillerislambers, S. Harpole, R. Dybzinski, J. Fargione, C. Clark, and C. Lehman. 2004. Does metabolic theory apply to community ecology? It's a matter of scale. Ecology 85:1797-1799. 
Vasseur, D. A. AND K. S. MCCANn. 2005. A mechanistic approach for modeling temperature-dependent consumer-resource dynamics. American Naturalist 166:184-198.

Vidondo, B., Y. T. Prairie, J. M. Blanco, and C. M. Duarte. 1997. Some aspects of the analysis of size spectra in aquatic ecology. Limnology and Oceanography 42:184-192.

West, G. B., J. H. Brown, AND B. J. ENQuist. 1997. A general model for the origin of allometric scaling laws in biology. Science 276:122-126.

West, G. B., J. H. Brown, And B. J. EnQuist. 1999a. The fourth dimension of life: Fractal geometry and allometric scaling of organisms. Science 284:1677-1679.
West, G. B., J. H. Brown, And B. J. EnQuist. 1999b. A general model for the structure and allometry of plant vascular systems. Nature 400:664-667.

\section{SOURCE OF UnPublished MATERIALS}

AmERICAN SOCIETy OF LimNOLOGY AND OCEANOGRAPHY. Unpublished data. Abstracts at www.aslo.org/meetings/santiago2005/ abstracts/SS37.htm

Received, May 2, 2005 Revised, November 8, 2005 Accepted, November 9, 2005 